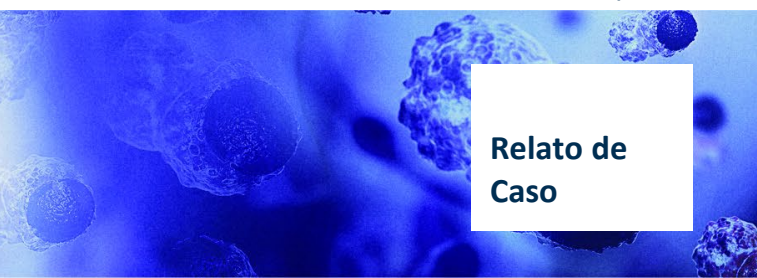

\title{
Terapia de privação androgênica em tumor avançado de glândula salivar: Relato de caso
}

\author{
Androgen deprivation therapy in advanced salivary gland tumor: Case report \\ Cláudia Graziele Rodrigues Santos ${ }^{1}$, Carolina Rossetti Rodrigues dos Santos ${ }^{1}$, Auro del Giglio ${ }^{2}$ \\ Como citar: Santos CGR, Santos CRR, del Giglio A. Terapia de privação androgênica em tumor \\ avançado de glândula salivar: Relato de caso. Clin Onc Let. 2020; Ahead of Print. \\ https://doi.org/10.4322/col.2019.003
}

\begin{abstract}
Resumo
O carcinoma de ducto salivar é um tumor maligno raro que representa 0.2 a $0.3 \%$ de todas as neoplasias malignas e 6 a $8 \%$ de todos os cânceres de cabeça e pescoço. Ele possui expressão para receptores androgênicos em 67 a $96 \%$ dos casos, de modo que a deprivação androgênica é uma opção de tratamento com taxa de resposta variando de 18 a $64.7 \%$. Relatamos o caso de um paciente do sexo masculino de 74 anos com diagnóstico de carcinoma de ducto salivar, sendo inicialmente submetido a parotidectomia direita seguida de radioterapia adjuvante. Após 4 anos de seguimento, evolui com recidiva linfonodal cervical, a qual foi tratada com ressecção cirúrgica completa seguida de quimiorradioterapia adjuvantes. Após um ano desse tratamento, evolui com recidiva sistêmica (doença metastática óssea, pulmonar e linfonodal), sendo submetido a 4 linhas de tratamento paliativo. Após a última progressão, em maio de 2018, realizada punção aspirativa de linfonodo cervical metastático e pesquisa de mutação HER2/neu e expressão de receptores androgênicos. A pesquisa resultou negativa para o primeiro, porém positiva para o último, sendo proposta quinta linha de tratamento com Bicalutamida $50 \mathrm{mg}$ ao dia. Paciente segue há 9 meses com bloqueio androgênico periférico apresentando boa tolerância e resposta parcial em exame de PET-CT.
\end{abstract}

Palavras chaves: Carcinoma de ducto salivar; terapia de privação androgênica; estudo de caso.

\begin{abstract}
The salivary gland tumor is a rare malignant tumor that represents 0.2 to $0.3 \%$ of all the malignant cancers and 6 to $8 \%$ of all the head and neck cancers. It has expression for androgen receivers in 67 to $96 \%$ of all the cases so that the androgen deprivation therapy is a treatment option with response rates varying from 18 to $64.7 \%$. We report the case of a 74 -year-old masculine patient with diagnosis of a salivary duct carcinoma, initially submitted to a right side parotidectomy followed by adjuvant radiotherapy. After four years of follow up, he develops recurrence in cervical lymph node which was treated with complete surgical resection followed by adjuvant chemoradiotherapy. After a year of this treatment, it evolves with systemic recurrence (metastatic bone disease, pulmonary and metastatic lymph nodes), being submitted to fourth palliative treatment line. After the last progression in May of 2018, it was performed a fine needle aspiration of the metastatic lymph node and screening for HER2/neu mutation and expression of androgen receivers. The screening turned out negative for the first one test, however it was positive for the latter and the fifth treatment line was proposed with Bicalutamide $50 \mathrm{mg}$ daily. The patient continues to receive androgen blockade in the last nine months, presenting good tolerance and partial response in examination of PET-CT.
\end{abstract}

Keywords: Salivary gland tumors; antiandrogen therapy; case report

\section{INTRODUÇÃO}

O carcinoma de ducto salivar é um tumor maligno raro que representa entre 0.2 a $0.3 \%$ de todas as neoplasias malignas e 6 a $8 \%$ de todos os cânceres de cabeça e pescoço. ${ }^{1}$ Compreende um grupo heterogêneo de carcinomas,

\footnotetext{
${ }^{1}$.Departamento de oncologia Clínica, Faculdade de Medicina do ABC, Santo André, Brasil

${ }^{2}$.Centro de estudo e pesquisa de Hematologia e Oncologia, Faculdade de Medicina do ABC, Santo André, Brasi

Financiamento: Não houve financiamento para este presente estudo

Conflito de interesse: Os autores declararam não haver conflitos de interesse que precisam ser informados.
} 
de caráter agressivo, associado a um alto risco de doença metastática a distância. A média de sobrevida global é de aproximadamente 3 a 5 anos após o diagnóstico., ${ }^{2,3}$ A ressecção cirúrgica é convencionalmente aceita como tratamento primário, associada ou não a radioterapia adjuvante. Nos casos de doença recorrente ou metastática, embora uma variedade de quimioterapias e terapias-alvo moleculares tenham sido testadas, um esquema padrão ainda não foi estabelecido. ${ }^{1,3}$ Sabe-se que o carcinoma de ducto salivar possui expressão para receptores androgênicos em 67 a $96 \%$ dos casos. ${ }^{2,3}$ Sendo assim, a deprivação androgênica é uma opção de tratamento neste cenário, demonstrando taxa de resposta de 18 a 64.7\% e aumento da sobrevida global quando comparado a cuidados paliativos exclusivos. ${ }^{3}$

\section{DESCRIÇÃO DO CASO}

Homem, 74 anos, hipertenso e portador de hiperplasia prostática benigna, com histórico de etilismo social e ausência de tabagismo, além de antecedente de tireodectomia total por carcinoma papilífero de tireóide. Apresentava antecedente carcinoma de ductos salivares de alto grau, sendo inicialmente submetido a parotidectomia direita, seguida de radioterapia adjuvante em outro serviço. Evoluiu com recidiva linfonodal cervical após 4 anos de seguimento. Realizado esvaziamento cervical nos níveis II, III, IV e V à direita, com anatomopatológico compatível com carcinoma de alto grau metastático. Realizado exame de PET-CT após procedimento cirúrgico, o qual confirmou ausência de doença residual. Foi então submetido a radioterapia (IMRT/IGRT) em concomitância com Cisplatina. Um ano após o último tratamento, apresentou recidiva sistêmica (nódulo pulmonar) e subcutânea em cicatriz cirúrgica cervical. Realizada biópsia de lesão cervical, a qual evidenciou carcinoma pouco diferenciado invasivo em derme e tecido celular subcutâneo com estudo imuno-histoquímico complementar favorecendo carcinoma de ductos salivares recidivado. Iniciado tratamento paliativo com Cetuximabe associado a Cisplatina e Fluorouracila. Permaneceu com doença estável por 6 meses, até que evoluiu com progressão linfonodal cervical. Iniciou segunda linha com protocolo metronômico (Ciclofosfamida e Metotrexate), porém desenvolveu nova progressão local após 2 meses de tratamento. Proposta terceira linha paliativa com Carboplatina e Paclitaxel, tratamento com o qual permaneceu com doença estável por 2 anos e 4 meses. Diagnosticada então nova progressão linfonodal cervical e axilar, além do surgimento de lesões ósseas secundárias. Realizada quarta linha paliativa com Nivolumabe e associado Ácido Zoledrônico devido a doença óssea. Após 3 meses de tratamento, apresenta nova progressão de doença em osso e pulmão. Realizada pesquisa em amostra tumoral de receptores androgênicos e HER2/neu. A pesquisa foi positiva para o primeiro e negativa para o último. Optamos por quinta linha paliativa com Bicalutamida $50 \mathrm{mg}$ ao dia associada ao Zometa trimestral. Paciente segue em uso das medicações há cerca de 9 meses, assintomático, mantendo boa tolerância ao tratamento e apresentando no último PET-CT realizado em março de 2019 captação discreta apenas em úmero proximal esquerdo (resposta completa em lesões pulmonares e linfonodais prévias e resposta parcial óssea).

\section{DISCUSSÃO}

Os tumores de glândulas salivares constituem um grupo heterogêneo de neoplasias que variam consideravelmente quanto ao sítio anatômico de origem, a histologia e ao comportamento biológico. Assim como na apresentação inicial da doença de nosso paciente, a parótida é sítio primário mais frequente, correspondendo a 80-85\% dos casos. Outros sítios incluem glândulas salivares submandibulares, sublinguais e glândulas localizadas ao longo da submucosa da boca e trato aerodigestivo superior. ${ }^{2}$

Os cânceres de glândulas salivares variam na sua agressividade e na propensão para recorrência e metástases à distância. Frequentemente, esses pacientes se apresentam com doença avançada ao diagnóstico, sendo 37.7 a $67.2 \%$ com doença localmente avançada estágio IVA e IVb (T4 ou N2/N3 sem metástase a distância) e 5.8 a 12,8\% com doença estágio 4c (metastática). ${ }^{3}$ Os sítios de metástase a distância mais comuns são os pulmões, seguidos por osso e fígado.

Embora não exista um fator de risco bem definido para o desenvolvimento da neoplasia de glândula salivar, deve-se levar em consideração a exposição prévia a radiação ionizante, infecções virais tais como Epstein Bar, papiloma vírus e vírus da imunodeficiência humana, assim como fatores ambientais. 
Para pacientes com doença ressecável, o tratamento inicial de escolha é o cirugico e deve ser feita complementação com radioterapia em pacientes considerados de alto risco, como comprometimento linfonodal, margem cirúrgica comprometida, extensão extracapsular, invasão angiolinfatica e perineural, etc. Já a radioterapia exclusiva é reservada para pacientes que apresentam lesões inoperáveis, seja pela extensão da invasão ou localização do tumor, de modo que a resseç̧ão resultaria em deficit funcional e/ou cosmético significativos.

Na recorrência, as opções de tratamento são limitadas pela terapia anterior recebida ou pela possibilidade de resgate cirúrgico. Já na doença metastática, embora a ressecção cirúrgica potencialmente curativa de um local solitário possa ser considerada, o tratamento é mais frequentemente paliativo.

No cenário metastático irressecável, a quimioterapia normalmente era o único tratamento disponivel, porém com baixas taxas e curta duração de resposta. A falta de eficácia da quimioterapia impulsionou pesquisas no campo das terapias alvo-moleculares. Um dos alvos avaliáveis é a superexpressão do HER2 (fator de crescimento epidérmico humano 2). ${ }^{4}$ Estudos prospectivos de braço único e relatos de casos de regimes de quimioterapia contendo trastuzumabe demonstraram respostas duráveis a tal esquema. Outra alternativa, seria o uso de bloqueador androgênico, uma vez que esses tumores freqüentemente expressam receptores androgênicos. A remissão parcial de um adenocarcinoma tratado com gosserrelina foi relatada pela primeira vez em 1994 e alguns anos depois, foi descrito remissão completa em paciente com expressão de receptor androgênico com diagnostico de adenocarcinoma de parotida recidivado, tratado com deprivação androgênica (bicalutamida $50 \mathrm{mg} /$ dia + Triptorrelina 3,75mg a cada 28 dias). Em 2011, foi descrita a atividade da Bicalutamida $150 \mathrm{mg}$ por dia em uma série de 10 casos de cânceres de duto salivar positivo para receptor de andrógeno, com taxa de resposta de $20 \%$ e tempo livre de progressão de 12 meses. ${ }^{4,5}$

Foi realizado um estudo fase II em que 36 pacientes com doença recorrente, metastática ou localmente avançada foram tratados com bloqueio androgênico combinado (Leuprolide mais Bicalutamide). Como resultado, houve 4 respostas completas e 11 respostas parciais, com taxa de resposta objetiva de $41,7 \%$. 12 pacientes apresentavam doença estável que durou pelo menos 24 semanas. A média de sobrevida livre de progressão foi de 9 meses e a sobrevida global média foi de 30,5 meses. Não foram reportados eventos adversos grau 4 e 5 e descontinuação foi reportado em apenas 1 paciente. ${ }^{1}$

A remissão completa da doença é um evento incomum para tumores sólidos com metástatase a distância, especialmente em pacientes com câncer de glândulas salivares recorrente ou metastático. Demonstrou-se que a atividade da terapia de deprivação androgênica é independente da natureza e do número de tratamentos previamente recebidos pelo paciente. Em adição, o tipo de quimioterapia recebido antes do bloqueio hormonal não tem influência na atividade da terapia de deprivação androgênica. ${ }^{4}$ No entanto, ainda faltam ensaios clínicos adequados para definir qual a melhor abordagem para pacientes com tumores metastáticos de glândula salivar, devido a raridade desses tumores.

\section{CONCLUSÃO}

Devido a raridade dos carcinomas de ducto salivar, e escassez de estudos, torna-se difícil definir um padrão de tratamento na doença avançada. Considerando o elevado percentual de expressão de receptores androgênicos desses tumores, devemos realizar a testagem destes receptores em todo paciente com diagnostico desta neoplasia, uma vez que o uso do bloqueador androgênico tem mostrado bons resultados, sendo uma opção de tratamento promissora.

\section{REFERÊNCIAS}

1. Fushimi C, Tada Y, Takahashi H, et al. A prospective phase II study of combined androgen blockade in patients with androgen receptor-positive metastatic or locally advanced unresectable salivary gland carcinoma. Ann Oncol. 2018;29(4):979-84. http://dx.doi.org/10.1093/annonc/mdx771. PMid:29211833.

2. Boon E, van Boxtel W, Buter J, et al. Androgen deprivation therapy for androgen receptor-positive advanced salivary duct carcinoma: a nationwide case series of 35 patients in The Netherlands. Head Neck. 2018;40(3):605-13. http://dx.doi.org/10.1002/hed.25035. PMid:29272069. 
3. Van Boxtel W, Locati LD, van Engen-van Grunsven ACH, et al. Adjuvant androgen deprivation therapy for poor-risk, androgen receptor-positive salivary duct carcinoma. Eur J Cancer. 2019;110:62-70.

http://dx.doi.org/10.1016/j.ejca.2018.12.035. PMid:30771738.

4. Locati LD, Perrone F, Cortelazzi B, et al. Clinical activity of androgen deprivation therapy in patients with metastatic/relapsed androgen receptor-positive salivar gland cancers. Head Neck. 2016;38(5):724-31. http://dx.doi.org/10.1002/hed.23940. PMid:25522335.

5. Jaspers HC, Verbist BM, Schoffelen R, et al. Androgen receptor-positive salivary duct carcinoma: a disease entity with promising new treatment options. J Clin Oncol. 2011;29(16):e473-6. http://dx.doi.org/10.1200/JCO.2010.32.8351.

PMid:21422415.

Endereço para correspondência:

Cláudia Graziele Rodrigues Santos.

Instituição: Hospital do coração - Hcor, São Paulo, SP - Brasil. Rua Araquã, 100, apto 93 - Edifício Renoir. CEP: 01306-020, Bela Vista, São Paulo, SP - Brasil.

Telefone: (11)968313095

E-mail: grazirodrigues.santos@yahoo.com.br 